Case Report

\title{
Adiponectin plasma levels decrease after surgery in pediatric patients with congenital heart disease
}

\author{
Chiara Caselli ${ }^{\text {a }}$, Massimiliano Cantinotti ${ }^{\mathrm{b}}$, Silvia Del Ry ${ }^{\mathrm{a}}$, Manuela Cabiati ${ }^{\mathrm{a}}$, Tommaso Prescimone ${ }^{\mathrm{a}}$, \\ Simona Storti ${ }^{\mathrm{b}}$, Bruno Murzi ${ }^{\mathrm{b}}$, Aldo Clerico ${ }^{\mathrm{b}}$, Daniela Giannessi ${ }^{\mathrm{a}, *}$ \\ a Consiglio Nazionale delle Ricerche (CNR), Institute of Clinical Physiology, Laboratory of Cardiovascular Biochemistry, Pisa, Italy \\ b Fondazione CNR-Regione Toscana "G. Monasterio", Pisa and Massa, Italy
}

\section{A R T I C L E I N F O}

Article history:

Received 27 April 2012

Accepted 12 July 2012

Available online 22 July 2012

\section{Keywords:}

Adiponectin

Pediatric patients

Inflammation

Metabolism

Congenital heart disease

\section{A B S T R A C T}

Objective: Adiponectin is a protein secreted by adipose tissue and involved in inflammatory process as well as in metabolic regulation. The aim of this study was to examine the response of plasma adiponectin to cardiac surgery in children with congenital defects to determine whether its measurement is associated to the response to injury.

Design and methods: Twenty-five pediatric patients undergoing heart surgery for correction of congenital defects were studied. Adiponectin plasma levels, obtained pre- and three times postoperatively, were determined by dedicated ELISA. Brain natriuretic peptide (BNP) plasma levels were also determined.

Results: Adiponectin levels are highest in the first month of life ( $p=0.004$ newborns vs. children) with a progressive fall in the next few years. After surgery, adiponectin increased slowly over a 1-month period, following an initial decrease in the first 3 days.

Conclusions: Adiponectin could be involved in the acute response to injury although further investigation into the relationship between adiponectin, glucose regulation and inflammatory process is necessary to examine the issue of the adiponectin decrease after surgery from a more integrated prospective.

(C) 2012 The Canadian Society of Clinical Chemists. Published by Elsevier Inc. All rights reserved.

\section{Introduction}

Metabolic responses to surgical injury are partly regulated by two processes, the acute phase and the glycemic response. During the first phase, Interleukin (IL)-6 stimulates the liver to produce proteins, such as C-reactive protein (CRP), proportionally to the dimension of the injury and typically reaching a peak within $72 \mathrm{~h}[1]$. Soon after, the glycemic response occurs, resulting in hyperglycemia proportional to the extent of the injury [2]. Regarding cardiac surgery, in pediatric patients cardiopulmonary by-pass induces a systemic inflammatory response, involving CRP [1,2] and IL-6 [3] and causes peri-operative hyperglycemia [4]. In neonates, hormonal and metabolic responses are distinct and more extreme than in adult patients and are associated with a high hospital mortality rate [1].

At the present, few data are available on interrelationship between inflammatory (acute phase) and glycemic metabolic injury-response parameters in association with injury severity and outcome in the pediatric cardiosurgery setting. Adiponectin, an adipocyte-derived protein, exerts anti-inflammatory and insulin-sensitizing actions [5]. In childhood,

\footnotetext{
* Corresponding author at: CNR Institute of Clinical Physiology, Laboratory of Cardiovascular Biochemistry, Pisa Research Area, Via G. Moruzzi, 156100 Pisa, Italy. Fax: + 390503152166 .

E-mail address: danielag@ifc.cnr.it (D. Giannessi).
}

the use of adiponectin as a biomarker for insulin sensitivity and/or as a risk factor for cardiovascular disease is gaining support [6].

The aim of this preliminary study was to check if plasma adiponectin is modulated by cardiac surgery in order to explore the possibility to use this protein as biomarker of the post-surgery response. For this, adiponectin levels were measured in pediatric patients before and after cardiac surgery performed to correct congenital defects up to 1 month, a time largely higher of the post-cardiac recovery. Few data are available on this issue [7], especially in children, so these results will be a starting point to plan a larger study devoted to investigate the role of adiponectin in the inflammatory/metabolic response after cardiosurgery in pediatric patients. Due to the relationship of natriuretic peptide on adiponectin production [8], plasma levels of brain natriuretic peptide (BNP) were also determined in the same patients at baseline.

\section{Material and methods}

We studied a group of 25 neonates and infants admitted to the Pediatric Cardiac Surgery Unit of Heart Hospital, Fondazione Monasterio, Massa, Italy (14 males, $64 \pm 72$ months, mean $\pm S D$ ) with various cardiac defects ( 2 aortic coarctation, 4 atrial septal defects, 1 congenital corrected transposition, 2 cardiomyopathies, 2 total anomalous pulmonary venous return, 3 transposition of the great arteries, 3 tetralogy of Fallot, 4 univentricular heart, and 4 ventricular septal defects). 
Children were evaluated before surgery by physical examination, standard 12-lead electrocardiogram, and chest X-ray. Diagnosis of congenital heart disease (CHD) was made by means of a standard trans-thoracic echocardiography according to international guidelines [9]. In the postoperative period, medical hemodynamic management involved epinephrine $(0.005-0.15 \mu \mathrm{g} / \mathrm{kg} / \mathrm{min})$, milrinone (0.5-0.75 $\mu \mathrm{g} \mathrm{kg} / \mathrm{min})$, dopamine ( $5-20 \mu \mathrm{g} / \mathrm{kg} / \mathrm{min}$ ), and noradrenaline $(0.05-0.5 \mu \mathrm{g} / \mathrm{kg} / \mathrm{min})$. Diuretic management usually involved furosemide ( $1-10 \mathrm{mg} / \mathrm{kg} /$ day). From all patients a blood sample was collected on the day of clinical ward admission (basal conditions). The time-course of adiponectin in the first month after surgery was determined in a sub-group of 21 children ( $45 \pm 62$ months, mean $\pm S D$, 13 males) undergone correction/pallation of CHD. Blood was collected at different times after surgery for routinary clinical evaluation.

Informed consent was given by all parents of newborns and infants enrolled in this study and the protocol was approved by the local ethics committee.

Plasma adiponectin was measured by a dedicated ELISA (Linco Research, St. Charles, MO, USA) previously described in detail [10]; plasma BNP was determined using the fully automated Access platform (Access Immunoassay Systems; Beckman Coulter, Inc., Fullerton, CA, USA).

Standard statistical analysis was carried out using the SPSS 16.0 for Mac (1989-2007, SPSS Inc., Chicago, IL, USA). Because adiponectin levels are not normally distributed, the original data were analyzed using non-parametric tests. A 2-tailed P-value $<0.05$ was considered statistically significant.

\section{Results}

Adiponectin values of CHD patients, divided according to age, are reported in Fig. 1. Adiponectin levels are highest in the first month of life ( $p=0.004$ newborns vs. children) with a progressive fall in the next few years, as previously found by us in healthy children (11). At baseline, BNP plasma levels in CHD children were $1328 \pm 535$ $\mathrm{pg} / \mathrm{mL}$ and showed a significant relationship with circulating adiponectin (Spearman's rho $=0.628, \mathrm{p}=0.002$ ) (Fig. 2), as observed in healthy children (11).

The time-course of adiponectin levels in CHD patients after surgery is shown in Fig. 3. After an initial decrease in the first 3 days after surgery, adiponectin levels increased slowly during the following 2 weeks, reaching a plateau value in 1 month (Fig. 3A). To avoid biological differences that could affect the pattern of the time course

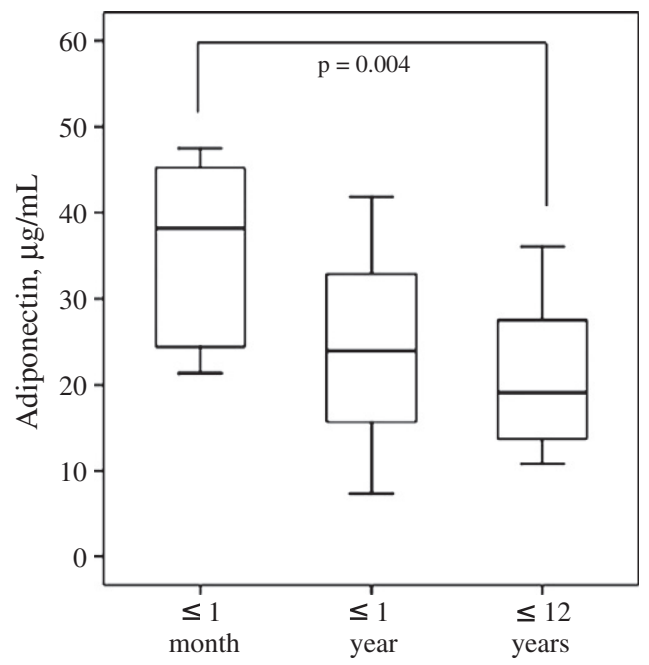

Fig. 1. Adiponectin plasma levels in CHD patients divided according to age: $\leq 1$ month $(n=8,6$ males $) ; \leq 1$ year $(n=5,2$ males $) ; \leq 12$ years $(n=12,6$ males). For each group, median values, 5th, 25th, 75th and 95th percentiles are reported. No significant differences were found between the $\leq 1$ year group and both $\leq 1$ month and $\leq 12$ years groups.

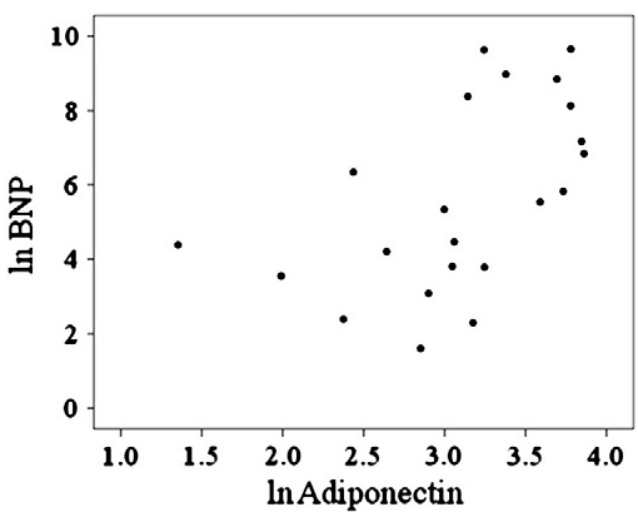

Fig. 2. Relationship between adiponectin and BNP at baseline: the values of the plasma levels after natural logarithmic transformation are reported (Spearman's rho $=0.628$, $\mathrm{p}=0.002$ ).

after surgery, probably masking the true effects, the percent variation of adiponectin with respect to baseline as a function of the post-surgery time has been also reported (Fig. 3B). The similar behavior of both the absolute and percent variations of adiponectin in the post-surgery suggests that the adiponectin response to injury is similar irrespective of biological differences such as the etiology of the congenital defects.

\section{Discussion}

The results from this preliminary study indicate that adiponectin significantly decreases in the first 3 days after surgery, with a progressive significant increase over the next 2 weeks (Fig. 3). This behavior,
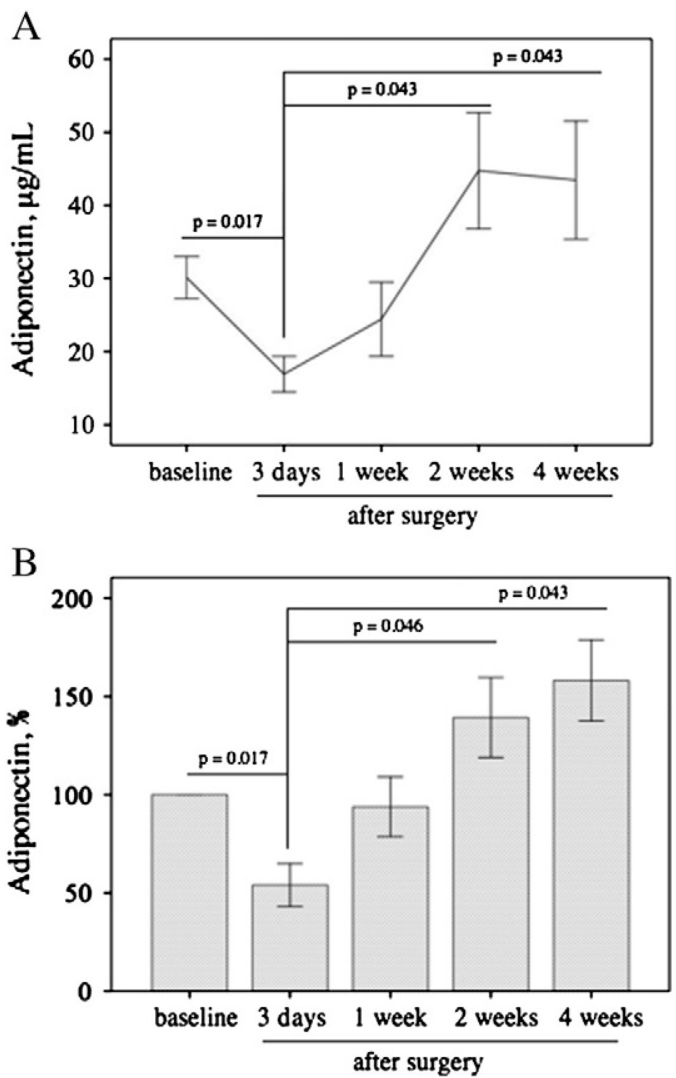

Fig. 3. Time course of adiponectin plasma levels up to 1 month after surgery: A. mean values $( \pm$ SEM) of adiponectin concentrations; B. percentage of change after surgery. No significant differences were found between adiponectin values at baseline and 1,2 and 4 weeks, respectively. 
although observed in a small number of patients, suggests the involvement of adiponectin in the metabolic response to injury. The fall of circulating adiponectin levels observed at 3 days coincides with the acute phase, characterized by high levels of inflammatory markers within $72 \mathrm{~h} \mathrm{[1].} \mathrm{Thus,} \mathrm{the} \mathrm{up-regulation} \mathrm{of} \mathrm{inflammatory} \mathrm{cytokines} \mathrm{could} \mathrm{con-}$ tribute to the decline of adiponectin levels through a decrease in its rate of synthesis in adipose tissue. The glycemic response is concomitant with this process and the lower adiponectin levels could play a part in promoting hyperglycemia. Adiponectin levels fall in obese and diabetic individuals as well as in subjects with coronary heart disease, due to inhibition by the inflammatory process, suggesting that the lowering of adiponectin levels may contribute to metabolic abnormalities [5]. Thus, in our setting the adiponectin could be a possible link between the acute and glycemic phases of the metabolic response.

On the other hand, our data closely agree with the observation that plasma adiponectin declines transiently following myocardial ischemia-reperfusion injury $[12,13]$. Adiponectin accumulates in the heart following injury largely as a result of leakage from the vascular compartment, contributing to the decline of circulating adiponectin levels. Furthermore, in damaged myocardial tissue, adiponectin participates in the wound healing process by binding the extra-cellular matrix, and explicates its cardioprotective properties against myocardial reperfusion injury by the inhibition of remodeling and apoptosis in cardiac myocytes and fibroblasts exposed to hypoxia-reoxygenation stress [12].

At baseline, adiponectin levels are highest in the first month of life, with a progressive fall in the following months and years in CHD subjects (Fig. 1), as previously found in healthy control subjects [11]. This decrease as a function of the age could be associated with differences between neonates, infants, and children in fat distribution, adipocyte size, inflammation and diet [14]. Moreover, the correlation between adiponectin and BNP at baseline suggests that BNP could contribute to the adiponectin levels in CHD patients, confirming the relation observed in healthy pediatric population [11].

\section{Conclusions}

Our data strongly suggest that plasma adiponectin is modified in response to cardiac surgery. This observation, which merits further analysis, in turn indicates that adiponectin evaluation may be useful to better assess the immediate metabolic response to injury, a critical issue in pediatric patients and in particular in newborns, in which deter- mination of adiponectin levels could also be important in addressing nutritional support in the postoperative period [15].

\section{References}

[1] Brunengraber LN, Robinson AV, Chwals WJ. Relationship of serum C-reactive protein and blood glucose levels with injury severity and patient morbidity in a pediatric trauma population. J Pediatr Surg 2009;44:992-6.

[2] Srinivasan V, Spinella PC, Drott HR, Roth CL, Helfaer MA, Nadkarni V. Association of timing, duration, and intensity of hyperglycemia with intensive care unit mortality in critically ill children. Pediatr Crit Care Med 2004;5:329-36.

[3] Gupta M, Johann-Liang R, Sison CP, Quaegebeur J, Friedman DM. Relation of early pleural effusion after pediatric open heart surgery to cardiopulmonary bypass time and systemic inflammation as measured by serum interleukin-6. Am J Cardiol 2001;87:1220-3.

[4] Moga MA, Manlhiot C, Marwali EM, McCrindle BW, Van Arsdell GS, Schwartz SM. Hyperglycemia after pediatric cardiac surgery: impact of age and residual lesions. Crit Care Med 2011;39:266-72.

[5] Ouchi N, Walsh K. Adiponectin as an anti-inflammatory factor. Clin Chem Acta 2007;380:24-30

[6] Steinberger J, Daniels SR, Eckel RH, Hayman L, Lustig RH, McCrindle B, et al. Progress and challenges in metabolic syndrome in children and adolescents: a scientific statement from the American Heart Association Atherosclerosis, Hypertension, and Obesity in the Young Committee of the Council on Cardiovascular Disease in the Young; Council on Cardiovascular Nursing; and Council on Nutrition, Physical Activity, and Metabolism. Circulation 2009;119:628-47.

[7] Takenaka K, Ogawa E, Wada H, Hirata T. Systemic inflammatory response syndrome and surgical stress in thoracic surgery. J Crit Care 2006;21:48-53 discussion 53-55.

[8] Tsukamoto O, Fujita M, Kato M, Yamazaki S, Asano Y, Ogai A, et al. Natriuretic peptides enhance the production of adiponectin in human adipocytes and in patients with chronic heart failure. J Am Coll Cardiol 2009;53:2070-7.

[9] Cantinotti M, Passino C, Storti S, Ripoli A, Zyw L, Clerico A. Clinical relevance of time course of BNP levels in neonates with congenital heart diseases. Clin Chim Acta 2011;412:2300-4

[10] Caselli C, Melaiu O, Maltinti M, Del Ry S, Cabiati M, Prescimone T, et al. A methodological reappraisal of total and high molecular weight adiponectin determination in human peripheral circulation: comparison of four immunometric assays. Clin Chem Lab Med 2010;48:561-8.

[11] Caselli C, Cantinotti M, Del Ry S, Cabiati M, Prescimone T, Storti S, et al. Relation between adiponectin and brain natriuretic peptide in healthy pediatric subjects: from birth through childhood. Nutr Met Cardiovasc Dis 2012, http:// dx.doi.org/10.1016/j.numecd.2012.03.004 [Jun 28, Electronic publication ahead of print].

[12] Shibata R, Sato K, Kumada M, Izumiya Y, Sonoda M, Kihara S, et al. Adiponectin accumulates in myocardial tissue that has been damaged by ischemia-reperfusion injury via leakage from the vascular compartment. Cardiovasc Res 2007;74:471-9.

[13] Kojima S, Funahashi T, Sakamoto T, Miyamoto S, Soejima H, Hokamaki J, et al. The variation of plasma concentrations of a novel, adipocyte derived protein, adiponectin, in patients with acute myocardial infarction. Heart 2003;89:667.

[14] Savino F, Petrucci E, Nanni G. Adiponectin: an intriguing hormone for paediatricians. Acta Paediatr 2008;97:701-5.

[15] Owens JL, Musa N. Nutrition support after neonatal cardiac surgery. Nutr Clin Pract 2009;24:242-9. 